\title{
in the Libraries:
}

\section{BY SUZAN A. ALTERI}

CURATOR

Baldwin Library of Historical Children's Literature

Student internships in the Baldwin Library have varied in format and research topic. Undergraduate student internships focus more on the inner workings of special collections librarianship and exhibition creation, while graduate student internships have ranged from course development to new digitization practices.

These internships are a great way to give students experience in creating public humanities work that bridges the gap between academic and community work.

Alice in Wonderland Pop-Up Book.

Robert Sabuda (2003)

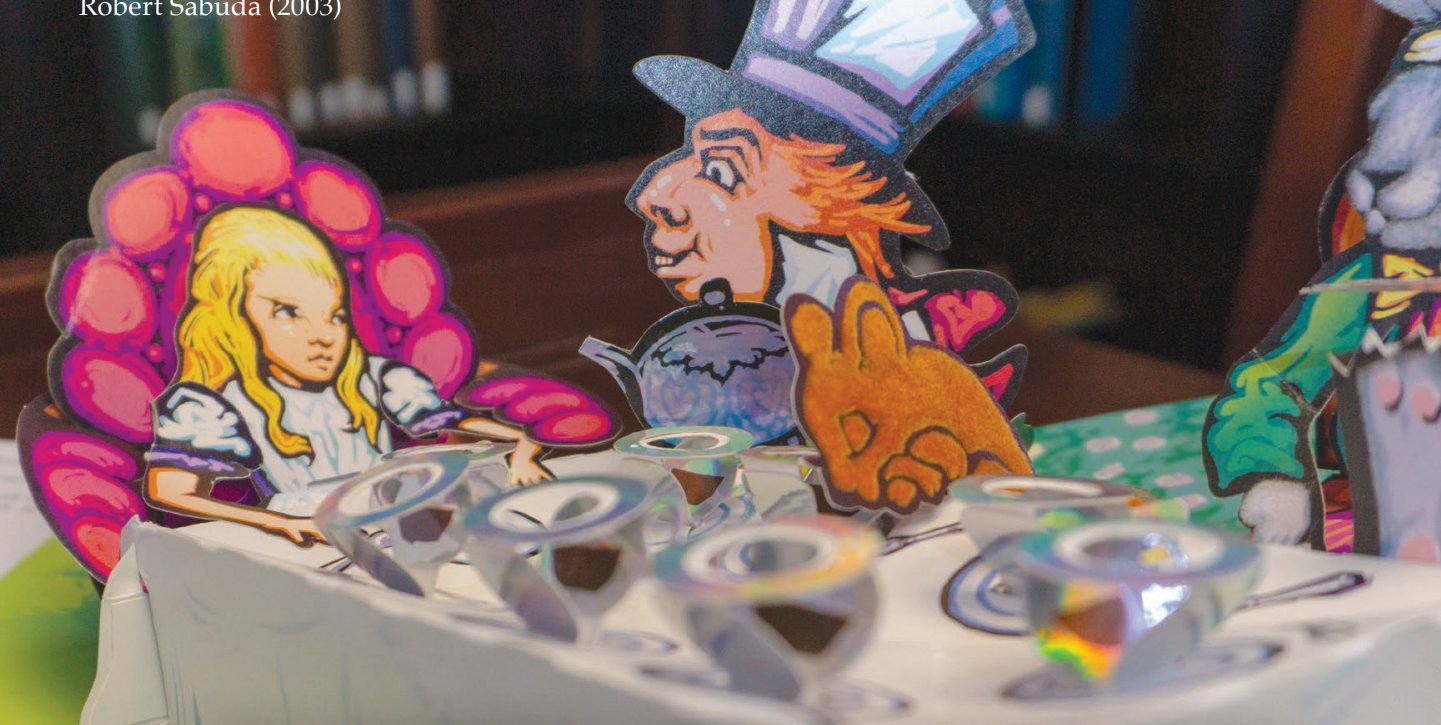

L.THE BALDWIN LIBRARY OF HISTORICAL

CHILDREN'S LITERATURE HAS OFFERED

UNDERGRADUATE STUDENT INTERNSHIPS SINCE 2012 AND GRADUATE INTERNSHIPS SINCE 2015. 


\section{Historical Caribbean Children's Literature}

\section{KELSEY CARPER}

INTERN

Curatorial and Bibliographical

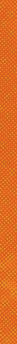

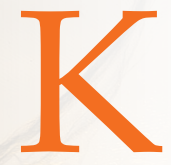

elsey Carper, a current Ph.D candidate in English, was offered a one-semester internship to support the UF Libraries' efforts to identify and digitize books related to the Caribbean and especially Cuba. Carper conducted in-depth bibliographical research into the Baldwin Library's historical holdings of children's literature about the Caribbean and prioritized titles for digitization and inclusion into the University of Florida Digital Collections. For her final project, Carper created a bibliography of titles, including annotations, to facilitate use of these materials by students, faculty, staff, and scholars. The bibliography was difficult to create since many titles and classifications did not accurately represent extensive hidden content in geography and culture books written by British and American authors during the Age of Empire. The internship provided Carper with a background into how special collections operate differently from circulating collections, and the importance of bibliography skills when conducting humanities research. 漟

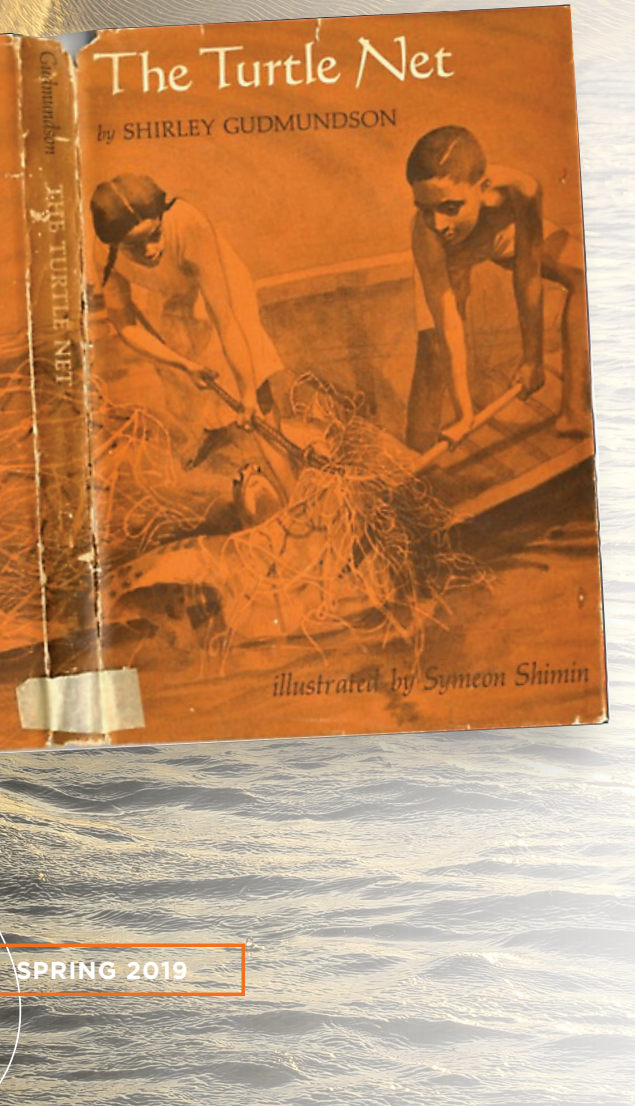

LEFT:

The Turtle Net.

Shirley M. Gudmundson, Author Symeon Shimin, Illustrator (1965)

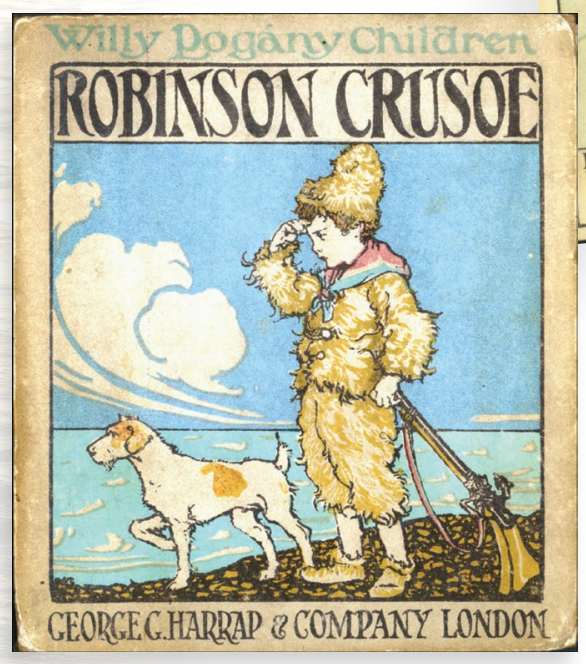

LEFT AND ABOVE: Robinson Crusoe. Daniel Defoe, Author Willy Pogány, Illustrator (1914) 